\title{
LAS ORDENANZAS MUNICIPALES DE GUADALAJARA DE MEDIADOS DEL SIGLO XIV. UN MUNDO EN TRANSICIÓN'
}

\author{
José Miguel López Villalba² \\ Universidad Nacional de Educación a Distancia
}

Recibido: 23 de julio de 2019

Aceptado: 20 de agosto de 2019

\begin{abstract}
Resumen
El objetivo de este trabajo es la revisión diplomática de las ordenanzas municipales, uno de los documentos más importantes, pero menos ensayados, entre los creados por la escribanía concejil medieval. El análisis se ha delimitado a las normas municipales más antiguas de la villa de Guadalajara, por su pretérita datación, por su gestión desde la corona y por su interesante contenido sobre el abastecimiento urbano. La principal aportación ha consistido en una exploración documental de las mismas. Asimismo, se han especificado perspectivas para futuros razonamientos diplomáticos a través de investigaciones comparativas. Nuestra propuesta permitirá conocer mejor la instauración y evolución de las ordenanzas municipales en los siglos XIV y XV en el reino de Castilla.
\end{abstract}

\section{Palabras clave}

Corona de Castilla, ordenanzas, concejos, oficiales, abastecimiento

\begin{abstract}
Abstrat
The objective of this paper is to make a review from a diplomacy perspective of the municipal ordinances, which are some of the most important documents among those belonging to the medieval chancellery, despite there is little knowledge about them as studies have been few. The analysis has been limited to the oldest municipal norms of Guadalajara, due to their antiquity, the way they were managed by the crown and due to their interesting content about urban supply. The main contribution consisted in their documentary exploration. Likewise, perspectives for future diplomatic reasonings through comparative research have been specified. Our proposal will therefore allow a deeper knowledge about the installation and evolution of the municipal ordinances in the $14^{\text {th }}$ and $15^{\text {th }}$ centuries in the kingdom of Castile.
\end{abstract}

\section{Keywords}

Crown of Castile, ordinances, council, officers, supply

\footnotetext{
El presente trabajo ha sido realizado en el marco del Proyecto de Generación del Conocimiento del Ministerio de Ciencia, Innovación y Universidades: "Notariado y construcción social de la realidad. Hacia una codificación del documento notarial (siglos XII-XVII)" PGC2018-093495-B-I00. (2019-2022).

2 Departamento de Historia Medieval y Ciencias y Técnicas Historiográficas. Facultad de Geografía e Historia. Universidad Nacional de Educación a Distancia. UNED. Correo electrónico: jlopez@geo.uned.es. ORCID: https://orcid.org/0000.0003.2299.3210.
} 


\section{Resumo}

O objectivo deste artigo é a revisão diplomática das leis municipais, um dos documentos mais importantes producidos pelos escrivãos medievais apesar de não ter merecido ainda muita atenção. A análise a enquadrar-se-irá na normativa municipal mais antiga de Guadalajara que foi fundamental não só pela abrangente cronología, mas também por causa da gestão da Coroa e pelo interessante conteúdo sobre os fornecimentos urbanos. A principal contribuição do presente trabalho consiste na pesquisa sistemática deste corpus documental. Algumas propostas e linhas futuras de investigação sobre a base dos elementos diplomáticos e um olhar comparativo serão também apresentadas. Por tanto, a nossa proposta pretende colaborar no melhor conhecimento da implementação e evolução das leis municipais nos séculos XIV e XV no Reino de Castela.

\section{Palavras Chave}

Coroa de Castela, leis municipais, conselhos, funcionários municipais, fornecimento

La villa de Guadalajara conquistada por Alfonso VI a los almorávides en 1085 disfrutó de un temprano fuero de repoblación otorgado por Alfonso VII en 1133³. En dicha carta se fijaban aspectos importantes como los contornos del alfoz de la villa, a la par que se otorgaban elevados beneficios a los futuros habitantes de la misma ${ }^{4}$. El efecto fue tan sobresaliente que la ciudad y su término se poblaron ágilmente, tanto, que en 1219 Fernando III concedía un nuevo fuero a la villa por el que se procuraba la buena gestión política y económica de sus vecinos ${ }^{5}$.

La siguiente noticia conocida sobre la ordenación de la villa son las que se han denominado como "las ordenanzas más antiguas de Guadalajara". Estas normativas fueron redactadas entre 1341 y 1346 . Dichas pautas destacan sobremanera porque establecieron un hito cronológico ya que se adelantaron a los postulados del ordenamiento de Alcalá de 1348, a la vez que dejaban entrever, por medio de articulados específicos, la estructura elemental de tan sobresaliente tipología del derecho local.

Las citadas ordenanzas serán estudiadas en estas páginas en su contexto histórico e historiográfico, a la par que se hará un análisis diplomático y de contenido. Aunque desde los años cuarenta del pasado siglo han sido objeto de interés, precisan de un trabajo de conjunto que haga hincapié, por encima de todo, en el estudio profundo de su tipología documental. La necesidad de una reasignación de su naturaleza dentro de la estructura de los cuadros de clasificación emanados por los concejos de la Baja Edad Media castellana ayudará a una mejor comprensión de la diplomática municipal.

\footnotetext{
Martin Prieto, Los Fueros de Guadalajara.

4 Debido a la pérdida del diploma original del Fuero de Alfonso VII en los desafortunados compases de nuestra pasada guerra civil, los estudios actuales se basan en los clásicos de, GARCía LóPEZ, La Alcarria en los dos primeros siglos, Pérez Villamil, Relaciones Topográficas, Pareja Serrada, Diplomática arriacense, y MuÑoz Romero, Colección de Fueros municipales.

5 El estudio referente de este Fuero es el de Keniston, Fuero de Guadalajara de 1219, que lo estudió en una versión existente en la Universidad de Cornell. Barrero García, y Alonso Martín, Textos de Derecho local.
} 


\section{Contexto histórico e historiográfico}

El reino de Castilla comenzó el siglo XIV arrastrando la crisis ocasionada por la muerte del rey Sancho IV. El fallecimiento, acaecido en abril de 1295, propició que su hijo Fernando todavía menor de edad recibiese la corona con el nombre de Fernando IV, por medio del juramento de fidelidad de las Cortes de Valladolid reunidas por procedimiento de urgencia en 1297.

Indudablemente fueron momentos graves. La declaración de guerra de Jaime II de Aragón unida a la anarquía existente en el reino y favorecida por las aspiraciones al reino de Alfonso de la Cerda, llevaron a la reina madre María de Molina, señora de Guadalajara a pedir la ayuda de las ciudades y villas más importantes. De igual manera, se toleró la instauración de Hermandades urbanas, un fenómeno político conocido desde largo tiempo

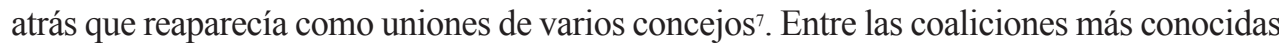
destacan las llevadas a cabo por las ciudades de Salamanca, Alba de Tormes y Zamora en mayo de 1295, cuyos postulados de asociación ante la defensa del rey en su minoría de edad reflejan al mismo tiempo consensos férreos y líneas de actuación poco claras, lo que puede ser producto de falta de anuencia entre los habitantes de las localidades implicadas ante condiciones concretas que supusiesen compartir intereses divergentes ${ }^{8}$.

Se trataba sin duda de una situación adversa a la Corona nacida como producto de la fermentación de ciertos deseos autónomos ambicionados por los concejos, cansados del vaivén regulador ante los elevados intereses intervencionistas iniciados ya por Alfonso $\mathrm{X}$, que impedían una diáfana definición de las expectativas concejiles. Efectivamente, las variadas intervenciones de dicho monarca para conseguir el control de los concejos medievales motivaron la creación de manifestadas tendencias por parte de los agentes sociales de las ciudades ${ }^{9}$.

La reina, doña María de Molina, ante este cúmulo de circunstancias desfavorables, procuraba asegurarse algunas fidelidades que garantizasen ayudas para su hijo. De este modo, y en busca del desenredo de tantos y tan complejos aprietos, inició un periplo para recabar apoyos que la llevó a visitar entre otras poblaciones, y dada su condición de señora de la villa, el concejo de Guadalajara ${ }^{10}$.

Es de interés detallar las escasas noticias conocidas en torno al paso del citado Fernando IV o de su madre por la villa de Guadalajara. Apenas se registran dos con cierta precisión. La primera en 1301, cuando María de Molina se detuvo en Guadalajara en su viaje para lograr la liberación del alcázar de Lorca, un capítulo más en el cruento enfrentamiento contra el rey aragonés ${ }^{11}$. Con posterioridad, en el mes de septiembre

\footnotetext{
6 La dignidad de señora de la villa de Guadalajara se concedió a las reinas consortes a raíz de la conquista de la villa en 1085. Layna SERrano, Historia de Guadalajara.

GonzÁlez Mínguez, “Aproximación al estudio”, pp. 34-35 y 29-60.

Barrios García, Monsalvo Antón, y Del Ser Quijano, Documentación Medieval del Archivo.

García De Cortázar, "Alfonso X y los poderes del reino", pp. 11-40.

10 LOAYsa, Crónica de los reyes de Castilla.

11 Idem, cap. VII, p. 118
} 
de 1304, llegó el rey a Guadalajara procedente de la ciudad de Toledo ${ }^{12}$. Ciertamente, las visitas regias no menudearon, lo cual resulta proporcionado para una villa que en la época mostraba un exiguo interés político y económico, motivado por su situación estratégicamente nula y su insuficiente importancia mercantil y política ${ }^{13}$.

La temprana muerte de Fernando IV propició un nuevo cambio de monarca sin que se hubiesen asentado las concepciones políticas necesarias para controlar un reino en reconstrucción. En la minoría del nuevo rey Alfonso XI, los grupos privilegiados de ciudades y villas buscaron alcanzar el protagonismo que durante largo tiempo habían abandonado $^{14}$. Durante los reinados de Sancho IV y Fernando IV, la nobleza había aprovechado la situación de debilidad en los ocupantes del trono castellano, de modo que pudo actuar con gran libertad ${ }^{15}$.

Por otro lado, aunque el rey Fernando IV no había tenido una excesiva vinculación con Guadalajara, su hijo y sucesor Alfonso XI fue pródigo en beneficios para la villa objeto de nuestro estudio ${ }^{16}$. En efecto, el rey Alfonso, después de una minoría excesivamente tumultuosa y poco productiva políticamente debido a las variadas insurrecciones que hubo de sufrir, pudo ejercer el gobierno de propia mano. Tras una primera unión conyugal con Constanza Manuel de Villena, que no llegó a ser consumada, y por lo tanto fue nula, su segundo matrimonio en 1328 con su prima hermana María de Portugal, hija de Alfonso IV, acabó por deteriorarse a los pocos años debido a su relación íntima con Leonor de Guzmán. A pesar de esta situación irregular, la reina legítima continuó ejerciendo sus labores como señora de la villa de Guadalajara. Con el desarrollo de esta tarea favorecedora procuró auxiliar en todo momento a sus súbditos arriacenses, en especial a los conventos y monasterios a los que ayudó con considerables cantidades para mejorar la fábrica de los edificios. De igual modo, como señora de la villa, otorgó en 1341 y 1346 una serie de normas que se pueden considerar como las primeras ordenanzas municipales de Guadalajara ${ }^{17}$.

En este análisis se mantendrán las citadas fechas como ciertas tras dos trabajos diferenciados. El primero analizar y contrastar las diferentes versiones documentales depositadas en El Escorial ${ }^{18}$ y en el Archivo Municipal de Guadalajara ${ }^{19}$ que han dado

\footnotetext{
Ibidem, cap. XI, p. 133.

3 Layna Serrano, Historia de Guadalajara.

4 Cañas Gálvez, Itinerario de Alfonso XI.

15 Martínez, "La Crónica y la Gran Crónica de Alfonso XI”, pp. 43-56.

16 Una extensa relación de los mismos la podemos ver en Layna Serrano, Historia de Guadalajara, I, p. 35 .

17 Pérez Villamil opina que existieron unas anteriores en tiempos de Fernando III que él mismo fecha en 1290, pero no aporta mayor razón sobre las mismas. PÉrez Villamil, Relaciones Topográficas de España, p. 66 .

18 Real Biblioteca del Monasterio de San Lorenzo de El Escorial, Códice X-II-19, «Ordenamientos y leyes de los reyes Enrique II, Juan I, Alonso XI, Enrique III, Juan II y Enrique IV; y Fuero y Ordenanzas de Guadalajara», fols. 120v-136v.

19 Libro copiador de Ordenanzas, privilegios y escrituras, [1540 ca.]. Archivo Municipal de Guadalajara (AMGU H52.1.- n 133096),
} 
como resultado la adjudicación positiva para las fechas datadas por eras y, en segundo lugar, explorar las opiniones de los anteriores estudiosos de las mismas.

En este sentido se debe comenzar revisando la versión difundida en los años cuarenta del pasado siglo por Francisco Layna Serrano, quien, posiblemente, solo conoció la traslación recogida en el citado libro copiador del concejo de Guadalajara. Sin la aparente comparación de esta fuente con otras versiones, dicho ensayista y, durante muchos años, toda la historiografía alcarreñista medieval han opinado que estas ordenanzas son, respectivamente, de 1379 y 1384 , aduciendo que se trata de un error del escribano que, al pasarlas a dicho libro, puso era y no año, generando un desacierto cronológico de treinta y ocho años ${ }^{20}$. La falta de controversia hizo que durante muchos años la mayoría de los analistas siguieran a Layna Serrano y por lo tanto, dieran por buenas sus afirmaciones con una renuencia que hizo del error dogma de fe.

En las últimas décadas del pasado siglo se volvió sobre la cuestión, encontrando en la hispanista francesa, Caroline Mignot, las primeras opiniones discordantes. Dicha autora, en un estudio de 1984, hablaba de estas ordenanzas situándolas en 1341 y 1346 . No obstante, lo hacía sin apostar decididamente por dicha cronología, ni abordar específicamente el asunto de su datación. Además, curiosamente, en ningún momento cita otras copias ni otros autores, aparte de la transcripción recogida en la obra de Layna, por lo que se ha de suponer que, a pesar de seguir al citado polígrafo, consideró que la datación por la era hispánica debía ser la correcta ${ }^{21}$.

Años más tarde, en 1995, José Miguel López Villalba presentó su tesis doctoral de sesgo paleográfico-diplomático y, comprobando las diferentes versiones de dichos preceptos, mantuvo los tiempos de 1341 y $1346^{22}$. En su razonamiento ampara la evidencia de que la copia estudiada por Layna es la más moderna por estar redactada a mediados de siglo XVI, frente a la que se debe considerar como una copia más antigua, la correspondiente a la versión existente en la biblioteca del monasterio escurialense. Si bien es cierto que ésta última versión se encuentra sin fechar, López Villalba afirma que fue escrita en letra cortesana evolucionada de la segunda mitad del siglo XV, siendo por tanto cien años más antigua que la existente en el libro copiador del AMGU. Además, en la data de la copia escurialense aparece claramente que la datación cronológica se lleva a cabo por era y no por años.

Por su parte, el profesor Pablo Martín Prieto en dos recientes aportaciones, una sobre los fueros de Guadalajara ${ }^{23} \mathrm{y}$ otra sobre la labor de algunas reinas propietarias de Guadalajara ${ }^{24}$, apuesta por datar su redacción a mediados del siglo XIV, adhiriéndose de modo contundente a la opinión del autor anterior.

\footnotetext{
Layna Serrano, Historia., t. II, p. 499.

Mignot, "Le municipio de Guadalajara", pp. 581-609.

López Villalba, Diplomática Municipal Medieval.

Martín Prieto, Los Fueros de Guadalajara.

Martín Prieto, "Notas sobre María de Portugal”, pp. 219-236.
} 
Las citadas ordenanzas se concedieron a través de tres grupos de disposiciones que se encargaron de normalizar diferentes asuntos, principalmente para mejorar algunos aspectos del abastecimiento de la villa. En la redacción de dichas normas quedaban excluidos capítulos referentes al derecho privado, penal o procesal y se reforzaban más los aspectos administrativos y económicos. Efectivamente, son unos cánones en los que predomina la organización política y económica de la villa por medio de la regulación de los pesos y medidas, caloñas, rentas, policía, sanidad, mercados y otras disposiciones de similar condición. No se ha de olvidar que los criterios contenidos son hijos directos de los fueros concedidos con anterioridad ${ }^{25}$.

La elaboración de las inaugurales ordenanzas, datadas en mayo de 1341, trajo a Guadalajara a dos delegados regios, Domingo Juan de Santo Tomé y Juan Martínez, jurado.

"En veynte e tres días de mayo, era de mill e trezientos e setenta e nueve años, vinieron a Guadalajara, Domingo Juan de Santo Tomé, vezino de Salamanca e Juan Martínez, jurado, por corregir los fechos de la tierra con carta de la reina e entre otras cosas fizieron hordenamiento ...."26.

Su llegada se produjo en un momento en que comenzaron a hacerse frecuentes las visitas de alcaldes veedores, jueces de salario y enmendadores a las poblaciones de realengo, todo ello en busca del mejor control de las citadas localidades. Igualmente aconteció con las que se promulgaron un lustro más tarde, en diciembre de 1346. En aquella ocasión otros dos funcionarios reales, Tel Fernández de Toledo y Garcí Alfonso Triguero de Toro, ambos alcaldes de la reina doña María y pertenecientes estrechamente a su servicio, acudieron a Guadalajara y, en colaboración con los dirigentes del concejo, acordaron e hicieron aprobar una nueva serie de reglamentos en dos sesiones que podemos asentar en los días $1^{27}$ y $22^{28}$ de dicho mes.

La vinculación de los citados comisionados con la corona no está claramente identificada, aunque en el desarrollo de la intitulación de los citados reglamentos se les reconoce explícitamente con el título de «jurados» y «alcaldes». Unas designaciones que quedan un tanto difusas en un tiempo donde no existía un claro esquema de la administración real en los niveles medios. Alguno de los estudiosos de la reina María de Portugal, como señora de Guadalajara, expone una filiación probable de los citados personeros ${ }^{29}$. El primero de estos procuradores, a los que dicho autor llama corregidores adelantando un tanto si no la figura de este tipo de pesquisidor si al menos la denominación, es

\footnotetext{
Alvarado Planas, Espacio y Fueros de Castilla-La Mancha.

Real Biblioteca de El Escorial, f. 120r.

Idem, f. 130r.

Idem, f. $134 \mathrm{v}$

29 Martín Prieto mantiene en un extenso discurso que dichos funcionarios reales podrían estar identificados por medio de algunos cargos que tuvieron un cierto protagonismo en la Corte. Martín PRIETO, "Notas sobre María de Portugal”, pp 221-222.
} 
Domingo Juan de Salamanca, jurado por cargo y ciertamente especializado en negocios jurídicos. Es un personaje cuyo desempeño administrativo se documenta con regularidad durante el reinado de Pedro I. Del segundo, Juan Martínez, no parece tan clara su identificación dentro del organigrama funcionarial de la monarquía, aunque parece coincidir con otro personaje de igual nombre que gozó de ciertos privilegios durante su adscripción a la administración de dicho rey.

Respecto a los dos oficiales que arribaron a Guadalajara a fines de 1346, Tel Fernández provenía de la administración regia de la ciudad toledana, donde al igual que el resto de sus compañeros, haría carrera posteriormente en época del rey Pedro I llegando a ostentar el oficio de alcalde mayor. Desde esta elevada posición ejecutó diversas gestiones de cierta notoriedad que acreditan su protagonismo en la cada vez más compleja administración regia. En lo que hace a Garci Alfonso de Triguero, su colocación como alcalde en tiempo de la reina María parece garantizada, así como posteriormente pesquisidor al servicio de la corona petrista ${ }^{30}$.

Llegados a este punto se han de rematar dos cuestiones. Una la cronológica, por medio de la acertada datación de López Villalba junto con la reciente y exhaustiva proposición de Martín Prieto, que permite situar documentalmente a los intitulantes comisionados por la corona en un tiempo inmediatamente posterior a la redacción de las reglas. La situación de dichos protagonistas en la administración central prestando servicio al rey Pedro I ayuda a zanjar un tema mal enfocado desde el principio, que hasta la aparición de pruebas más fehacientes se debe considerar cerrado en las fechas propuestas.

En segundo lugar, el marcado cariz intervencionista de la corona alumbrado por medio de la cuestión de los nombramientos de los citados autores de los estatutos. Los enviados responden de sus actos ante la reina, como titular de la villa. Su intervención, como delegados regios, deja abierto un camino que responde a un claro perfil que se incrementara con el paso de los años. En cualquier caso, podemos referirnos a estos personajes como funcionarios de la casa real, puesto que acudieron a la villa regia Guadalajara provistos de la autorización y orden de la reina para "corregir los fechos de la tierra". Por ello también se ha de deducir que hubo una petición previa del concejo de la villa ante el presunto desconcierto por tratar algunos aspectos comerciales y de abastecimiento, tal como se puede deducir de los intereses perseguidos en las regulaciones aprobadas. Estos autos jurídicos son producto de los años previos al cónclave a cortes celebrado en Alcalá de Henares en 1348, que resultaron ser los parlamentos más eficaces de la administración de Alfonso XI sobre todo en lo que a legislación sobre el control de las ciudades se refiere ${ }^{31}$. Por medio de lo que se ha venido en llamar el ordenamiento de Alcalá, el citado soberano consiguió que se aprobara un corpus jurídico que fuera la regla a seguir. La efectividad de dichos procedimientos les hizo prolongarse en el uso durante el resto de la Edad Media, hasta la llegada de las Leyes de Toro de 1505. En la asamblea de Alcalá de Henares se concretó una normativa que partía de la dispersión de

\footnotetext{
30 Idem, p. 224.

31 Álvarez Palenzuela, "La Corona de Castilla en el siglo XV”, pp. 79-94.
} 
las normas locales y de la clara indefinición jurídica que existía en el reino de Castilla. Un complejo punto de partida sobre los restos del arcaico concejo posibilista desde el que iniciar una sustitución sin retorno de la gobernanza urbana. De este modo se abría el camino hacía el definitivo control de los cabildos municipales por los agentes administrativos y judiciales de la monarquía, si bien a largo plazo se propició que fuesen las minorías oligárquicas de las ciudades, entre ellas la baja nobleza, las que acabaran monopolizando el gobierno local ${ }^{32}$.

\section{Las ordenanzas municipales: puntal de la construcción del concejo}

En los conocidos cuadros de tipología documental concejil que aportó Pino Rebolledo, en sus dos obras más conocidas, incluía las ordenanzas dentro del grupo de los diplomas del concejo y en el subgrupo de los de régimen interior ${ }^{33}$. Por su parte, la doctora María Josefa Sanz Fuentes, pionera de dichos estudios diplomáticos, participó de los mismos postulados en uno de sus trabajos iniciales sobre documentación municipal ${ }^{34}$. Recientemente, la citada profesora ha considerado que las ordenanzas tienen otro destino instrumental, adscribiéndolo al grupo de los documentos de relación del concejo, y así lo manifiesta en alguno de sus postreros trabajos sobre diplomática concejil ${ }^{35}$.

La complejidad que presenta esta tipología nos hace acudir a su definición en el Diccionario de Autoridades, que nos aclara su objetivo primordial "aquella que está hecha para el régimen y buen gobierno de las ciudades o comunidades" "36. Se ha de entender que, según la tradición de la doctrina del Derecho local español, el régimen es la forma de gobierno, medios jurídicos, económicos y personales de la institución, y por lo tanto, todo aquello que trata de hacienda, patrimonio y personal del concejo. En consecuencia, las ordenanzas deberían ser incluidas entre la documentación emitida por el concejo y que es denominada de régimen interior. Pero no es menos cierto que, si bien debemos atribuir la terminología de régimen interior a todas aquellas ordenanzas específicas para el funcionamiento del concejo, se ha de dejar para otras normativas menos delimitadas, las definiciones de "buen gobierno" y "regulación económica"37.

En lo que respecta al análisis de las ordenanzas municipales, Pino Rebolledo no hizo una exploración diplomática de las mismas, a pesar de la exhaustiva indagación que realiza sobre la amplia tipología concejil recogida en sus cuadros clasificatorios. Otros autores apenas presentan livianos apuntes sobre este tipo de exploración, pero sin llegar a desbrozar la que se puede considerar espinosa estructura de las mismas, de tal suerte que se puede afirmar que han sido mínimos los trabajos que han tratado esta cuestión.

\footnotetext{
Monsalvo Antón, El sistema politico concejil.

Pino Rebolledo, Diplomática Municipal.

SAnz Fuentes, “Tipología Documental de la Baja Edad Media”, pp. 193-208.

SAnz Fuentes, "De Diplomática concejil castellana”, pp. 535-548.

Diccionario de Autoridades.

37 Para el estudio de las ordenanzas bajo la óptica de la historia del Derecho. LADERo QuESADA, y GALÁN PARra, "Las ordenanzas locales” pp. 221-243, y Corral García, Ordenanzas de los Concejos castellanos.
} 
No obstante, conviene destacar las exploraciones presentadas por Riesco Terrero para algunas ordenanzas de origen real ${ }^{38}$, y la pionera disertación de Carrilero Martínez para las municipales, que durante muchos años fue la única de su género ${ }^{39}$.

En el primero de los ensayos, el profesor Riesco presentaba una estructura documental de las ordenanzas que, al emanar de la cancillería real, parecen obedecer al sistema orgánico clásico que exterioriza la documentación solemne con sus tres partes: Protocolo, Cuerpo y Escatocolo, bien diferenciadas. Cuando se habla de documentación concejil conviene centrarse en el segundo estudio, en el que Carrilero sugiere una distribución clausular que queda en los siguientes términos: Introductio, Corpus y Promulgatio.

Sin entrar a una crítica pormenorizada de su razonamiento, entendemos que desplegó una opción demasiado generalista que no se corresponde con una realidad que se advierte mucho más complicada. Diplomáticamente hablando, las ordenanzas municipales no se presentan como una estructura repetida, ni tan siquiera similar, sino que adoptan diferentes formas. Tantas como sean capaces de recrear para contener los cánones solucionadores que el gobierno concejil determine en cualquier ocasión, ante los variados problemas que presente la vida cotidiana del concejo y sus vecinos.

A modo de ejemplo, y entre los múltiples orígenes de que estéticamente exhibían dichos diplomas, se puede argüir la necesidad urgente que precisaban algunos concejos acerca de la fijación de una norma o normas ejecutivas. Esta situación de apremio puede derivar en que estas pautas se asienten como un acuerdo más, dentro de una suma de compromisos en una reunión ordinaria del concejo, sin tener otra vida instrumental.

¿Qué futuro diplomático les espera a estos preceptos que se han de perder en el mar de papel que supone un libro de acuerdos? Es difícil de consignar. Posiblemente, con el tiempo se trasladarán a un corpus normativo más amplio y perdurarán en su medio natural como capítulo de una normativa extensa. Pero, por otro lado y como se ha dicho, alcanzarán a diluirse entre los variados asientos que recoge cualquier libro de actas, de tal suerte que serán difíciles de encontrar por los investigadores. En el caso de los diplomatistas resultará incluso más complejo intentar resolver el enigma de un comentario diplomático a base de normas individualizadas y desubicadas. Es decir, que la orientación del estudio residirá en el soporte que vehicule la ordenanza, que podrá ser de tantas naturalezas como necesidades tuviesen en la oficina municipal.

Por lo tanto, las ordenanzas son un documento que difícilmente se encuentra exento, como tipología individualizada, en los fondos archivísticos. Muy al contrario, porque lo habitual es que aparezcan en actas concejiles, diplomas regios, cartas, traslados, códices o libros copiadores, entre otros soportes. En el caso que se presenta en estas páginas, las normas concejiles más antiguas conocidas de la villa de Guadalajara aparecen insertas dentro de un largo proceso reflejado en un testimonio de acuerdos. Dicho tipo diplomático se caracteriza porque en él se encuentra la descripción de todas las actuaciones

\footnotetext{
38 Riesco Terrero, “Análisis jurídico-diplomático”, pp. 51-70.

39 Carrilero Martínez, "Diplomática municipal”, pp. 71-90.
} 
llevadas a cabo por el concejo para resolución de algunas situaciones. En este caso se recogerá por extenso todo el proceso de la redacción de las citadas medidas.

Las primeras normativas concejiles que se conservan de la villa de Guadalajara hacen referencia a los años 1341 y 1346, y, en la actualidad, se pueden encontrar en dos versiones, tal como se dijo con anterioridad. La copiada en el "Libro de Ordenanzas, privilegios y escrituras", que está datado a mediados del siglo XVI, y se custodia en el Archivo Municipal de Guadalajara, será la utilizada en este trabajo, debidamente cotejada con la otra copia más remota, depositada entre los fondos de la Biblioteca del Real Monasterio del Escorial. Entre ambas versiones no hay diferencias sustanciales en su exposición, salvo las propias producidas por los lapsus de los escribanos que acometieron sus transcripciones.

Estas ordenanzas que hemos clasificado como de "buen gobierno", reflejan la capacidad de intervención y dirección del concejo en la vida de la comunidad, aunque, en aquel momento se hiciesen por medio de la intervención regia que claramente asesora y dirige la redacción de las mismas a través de los oficiales que envió la reina doña María de Portugal, señora de la villa.

Por encontrarse insertas dentro de otro documento, un testimonio de autos, se hará un sucesivamente el análisis diplomático del ambos tipos para comprender mejor el ritmo clausular que los caracteriza. Dicho procedimiento permitirá conocer la estructura de las ordenanzas a través de una de las múltiples piezas documentales que, directa o indirectamente, consiguen transportar dichas sistematizaciones municipales. El estudio documental constará de dos intervenciones diferenciadas. En primer lugar, se analizará la tipología diplomática de los testimonios de acuerdos, que contiene las susodichas medidas y, a continuación, la de las ordenanzas acogidas en la compleja redacción de los primeros.

\subsection{Los testimonios de acuerdos: solución documental}

Los testimonios de acuerdos son reflejo de las actuaciones y sus consiguientes diligencias que se llevan a cabo respecto a un asunto concreto. Entre ellas se pueden destacar juramentos, pregones, validaciones testificales y suscripciones de escribanos. En pocas palabras, un procedimiento factible para documentar muchas de las intervenciones del concejo que necesitan fijación por escrito.

En cuanto a la forma diplomática, generalmente adoptan la estructura básica de acta, iniciándose por la data. Es en este punto donde puede haber cierta confusión con la citada tipología de las actas normalizadas, que nacen como resultado de las sesiones de concejo ${ }^{40}$. No obstante, se ha de tener en cuenta que la característica documental de cualquier diploma es la suma de las tipologías formal y jurídica, y que ambas deben tenerse presentes para definir un tipo concreto. Por ello, si bien los libros de acuerdos de sesiones y los testimonios de acuerdos son actas desde el punto de vista formal, las primeras tratan de todos los

40 López Villalba, Las Actas de Sesiones, 1997. 
actos documentados en una sesión, es decir, de la totalidad de acuerdos en cada una de las reuniones diferentes entre sí, siendo su resultado final, el libro de actas. Es decir, un reflejo autorizado del conjunto de deliberaciones en un tiempo concreto. El propósito de las actas de sesiones es recoger las decisiones adoptadas en la propia reunión del cabildo con toda la variedad de asuntos tratados durante la misma y las posteriores disposiciones sobre ellos. Por el contrario, el objetivo de los documentos denominados como testimonios de acuerdos, es la relación de las providencias concretas sobre un mismo asunto. Por tanto, el testimonio de acuerdos presenta unidad temática. Se puede ver claramente en el ejemplo que se muestra, el reflejo de unas ordenanzas, mientras que el contenido de las actas está cumplimentado por medio de la diversidad temática. Otra diferencia notoria entre ambos documentos es que las actas llevan la suscripción de todos los intervinientes, mientras que el testimonio de autos solo exhibe la firma original del escribano.

En resumen, aunque entre el acta de sesiones y el testimonio de acuerdos aparece habitualmente el uso de una misma forma diplomática básica, la de acta, lógicamente, siempre lo hará con intenciones documentales diferentes, porque las actas de sesiones se forman y se registran en un solo libro con la finalidad de dejar constancia de la actuación del concejo, que figura, generalmente, como autor único de la actio y la conscriptio documental. En cambio, los testimonios de acuerdos se forman con la finalidad de relatar todo lo que ha ocurrido en relación con un asunto concreto. Por lo tanto, lo verdaderamente significativo es el objeto a documentar, es decir, el tema concreto, aunque se presente por medio de diversas acciones concatenadas. Naturalmente, los testimonios de acuerdos son documentos que presentan asiduamente cierta complejidad en cuanto a la estructura diplomática, pero en los que puede hacerse un intento de distribución marco de las cláusulas diplomáticas. En realidad, estas aparentes discrepancias, resultantes de documentar un asunto por medio de dos formalidades diferentes, son intemporales. Pensemos por ejemplo en la divergencia entre los actuales libros de resolución de alcaldía y los expedientes.

En el caso que nos ocupa, los tres corpus de ordenanzas de Guadalajara que fueron redactados entre 1341 y 1346 se presentan arropados documentalmente por los mencionados testimonios donde se narrarán los acuerdos referentes a un asunto concreto. En este caso es el resultado de la regulación de la vida ciudadana, por ello encontraremos en sus artículos con un contenido de variados aspectos. Su estructura comienza redactada en forma de acta por medio de un protocolo inicial que detalla, en primer lugar, la data tópica y crónica, haciendo constar el nombre del lugar y el día del mes junto con el mes corriente y el año, que puede presentarse de manera literal o numérica. Estos modelos, tal como se ha significado, están computados en era hispánica.

La data deja paso a la verificación del acto de la asamblea, que llevará implícita la intitulación de los autores, en algunos casos general o institucional. En ciertas oportunidades, se presenta como autor la persona jurídica, "el conçejo", junto con la relación de las autoridades que los componen. En otros esquemas, es encabezada por algunos personajes que teniendo atribuciones para ordenar el concejo, sin embargo no pertenecen al mismo, como sucede en el presente objeto de estudio. Dada la similitud de la estructura que pre- 
senten los tres corpus, se han seleccionado como patrón los modelos correspondientes a las dos últimas normativas, que fueron redactadas los días 1 y 22 de diciembre de 1346. La actio empieza en las primeras líneas del testimonio del primero de diciembre, donde se individualiza la relación personal de todos los intitulantes, desarrollada según un cierto orden jerárquico. En primer lugar, se comenzará por los personeros enviados desde la corte, que actuarán como alcaldes de la reina propietaria de la villa, para continuar con la nómina de los miembros del concejo que se encuentran presentes en este importante asunto, detallando su categoría justificadora de pertenencia al cabildo municipal, tal como vemos para el ejemplo del uno de diciembre.

"Tel Fernández de Toledo, alcallde mayor por la rreyna e Garçi Alfonso Triguero de Toro, alcallde de la dicha señora de las alçadas de casa de la dicha señora, ... y estando ý Garçi Pérez Gallego e Alvar Pérez e Diego... " ${ }_{41}$

Es en este momento cuando se aprovecha para concretar la data tópica concreta a través de una localización de gran precisión:

“...estando en las casas de vn (sic) Abrahén Alfandari, do posa el dicho Tel Fernández, alcalde" $"$.

En el siguiente testimonio, datado en 22 de diciembre de 1346, encontramos nuevamente una data tópica que hace referencia, como en el caso anterior, a una casa particular, que en este caso resulta ser la morada del escribano ${ }^{43}$.

Las causas que habían impulsado al concejo de Guadalajara a enviar una petición a la reina para solucionar un arreglo de algunos aspectos para el mejor gobierno de la villa, no se concretan. Únicamente tenemos una constancia indirecta del hecho por los intitulantes, que aparece reflejada, en las primigenias líneas de los cánones de mayo de 1341. Un ejemplo de la temprana resolución iusiva que afectará al conjunto de la inseparable redacción articular:

"por corregir los fechos de ella con la carta de la rreyna e entre todas las cosas que hizieron, hordenaron como pasase en la tierra, como adelante dirá" ${ }_{44}$.

En este momento de la redacción se presenta una justificación del cónclave, por medio de una referencia explicativa de la presencia de los oficiales reales en la villa, y el por-

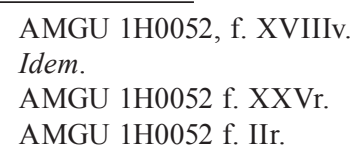


qué de que se hayan juntado con los prohombres de la misma, para redactar una serie de ordenamientos que mejoren variados aspectos:

"E dixeron que ellos entendiendo que es serviçio de la rreyna y pro de este dicho lugar que acordavan de fazer algunos hordenamientos..." 45

Aunque no se deja evidencia escrita de la presencia del escribano, ni mucho menos la certeza de su nombre y apellidos junto con el cargo y donde lo ejerce, sí se explicitan nominalmente los testigos que darán fuerza al acuerdo y que con la expresión "de yuso escriptos" quedan referenciados a las posteriores validaciones que garantizarán la validez jurídica de lo dispuesto ${ }^{46}$ :

Se trata, como ya anunciamos, de actuaciones externas al concejo pleno que se harán efectivas por medio de comunicaciones testimoniales y que únicamente en el momento de la reunión deben ser presentadas ante el pleno del cabildo. Será en ese ayuntamiento cuándo se lleven a cabo las diligencias que haya lugar y que puedan alcanzar la pertinente fuerza reglamentaria. Estos documentos, en este caso el completo desarrollo capitular de las ordenanzas, pasan a ser un conjunto extendido de insertos que bien podrían hacer de expositivo si no fuese porque con posterioridad siguen apareciendo sucesivos testimonios con sus respectivas validaciones. En realidad, no estamos ante una unidad archivística simple sino compleja, que presenta una serie de hechos certificados por el rogatario y validados testificalmente sobre un mismo asunto.

Tras asegurarse de la validez de la carta y anunciarlo ante el conjunto del cabildo, se copia el documento de "verbo ad verbum":

"E los quales hordenamientos fueron mostrados e leídos ante los sobredichos, son estos que se siguen..." ${ }_{47}$

Insistimos en la complejidad de lo presentado, de modo que todos los hechos referentes a esta cuestión se irán sucediendo ordenadamente y se insertarán unos a continuación de otros, como si de un precedente de los actuales expedientes se tratase.

\subsection{Análisis diplomático de las ordenanzas municipales}

Las ordenanzas antiguas de Guadalajara, al encontrarse insertas en un documento de reconocida complejidad, presentan la particularidad de que ambos documentos, continente y contenido, comparten algunas de las cláusulas esenciales. Comenzando por la

\footnotetext{
AMGU 1H0052, f. XXVr.

46 Idem.

47 AMGU 1H0052, f. XXVIr.
} 
data, elemento esencial para dejar constancia del momento en que se hicieron posible, es decir, de la conscriptio observamos que responde a sus particularidades crónica y tópica. En la primera se reflejan día, mes y año, computado por la era hispana, tal como vimos para los ejemplos preliminares ${ }^{48}$. La data tópica, igualmente ejemplificada con anterioridad, sitúa a los actores en lugares muy concretos

En otro apartado se explicó que no se sintetizaban las causas que impelieron al concejo a enviar una súplica a la reina doña María, propietaria de la villa, para que ordenase solucionar las complicaciones que les acuciaban. La oportuna llegada de los oficiales regios propiciaría con seguridad que se testimoniasen todos los pasos del proceso ordenancista, gracias a lo cual se tienen ciertas constancias indirectas del hecho. Estos alcaldes de la reina, justifican su advenimiento y ulterior actuación a través de una disposición general iusiva que afectará por igual a todos los artículos:

“por corregir los fechos de ella con la carta de la rreyna”" 49.

A partir de este momento comienza el desarrollo articular de las ordenanzas, que se verán introducidas por un brevete colocado siempre encima y en el centro de cada artículo, que nos aclara sucintamente el contenido del mismo:

\section{“Hordenança primera, de panaderas y almotaçenes" ${ }_{50}$.}

Los artículos se manifiestan a modo de cuerpo documental singularizado, estando divididos por dos cláusulas fundamentales, la dispositiva y la sanción. Por medio de la primera, e introducidos por el verbo "hordenaron", que indica la capacidad de elaboración de normas, se puede conocer detalladamente el contenido de lo decretado en todos sus aspectos. La sanción, como necesario refuerzo y garantía de lo dispuesto, se sitúa a continuación, sin ningún tipo de interrupción, y está formada por las cláusulas coercitivas que especifican las penas pecuniarias y corporales correspondientes, que irán aumentando con la contumacia del trasgresor. La repetición de ambas cláusulas genera una rigidez diplomática del tipo: disposición-sanción, que se rompe en escasas ocasiones y siempre en aquellos apartados que presentan mayor dificultad de desarrollo:

"Hordenaron que las panaderas que tengan pesos çiertos de treynta honças la mayor e que estas pesas que sean para siempre... por la primera vegada, diez maravedis e por la segunda otros ocho maravedís e por la terçera que la pongan en la horca"s1.

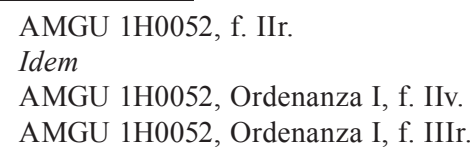


A veces se presenta otra disposición más breve junto con la pena correspondiente, previa reseña de lo trasgredido:

"E que las panaderas que non sean tenudas de vender pan en el forno ni en su casa, salvo en la plaça, so pena de los dichos diez maravedís ", ${ }_{52}$.

Una vez detallada la forma básica de artículo, podemos decir que esta estructura se repite continuamente introduciéndose los capítulos por medio de un "incipit", que posee la conocida partícula, "otrosi", como única puerta de entrada. Por otro lado ayuda a dar comienzo al dispositivo, ya que el verbo de ordenamiento al que correspondería hacer referencia a la capacidad legislativa, no suele aparecer:

"Otrosí, que los carniçeros que tengan buenas pesas de fierro e que pesen bien la carne e que los almotaçenes que tengan un peso en la plaça... "53

Este tipo de redacción es la más habitual, pero no todos los artículos presentan una rigurosidad definida entre la disposición y la sanción. Cuando esta quiebra sucede, lo hace por ausencia de las fórmulas penales y entonces aparece la exposición de motivos y la disposición con el verbo referencial, "mandamos":

“Otrosí, en rrazón que los almotaçenes e el juez lievan de los que traen la caça e el pescado fresco a vender a la villa algo de esto que non es fuero nin de derecho, mandamos que non lleven de aqui adelante" ${ }_{54}$.

La fractura de la citada tensión se puede producir igualmente por una presentación articular más intrincada. En estas circunstancias, desarrolladas tras el recurrente íncipit "otrosi", se pueden encontrar las tres partes esenciales del cuerpo documental: Exposición, disposición y sanción.

La exposición, que suele ser breve y genérica, es del tipo:

"Por las vinnas que reçiben gran danno en muchas maneras..." 55

La disposición se plantea a continuación por medio del verbo de mandato legislativo:

\footnotetext{
Idem.

AMGU 1H0052, Ordenanza II, f. IIIv.

34 AMGU 1H0052, Ordenanza III, f. IIIv.

55 AMGU 1H0052, Ordenanza XX, f. IXr.
} 
"Hordenaron que los cavalleros de las vinnas que... "“s6

Por último, la sanción intentará a través de las cláusulas penales hacer más eficaz lo dispuesto en el artículo:

"De todos los omes que fallaren en las vinnas, por la entrada que lieven de cada uno diez maravedís por cada ... E si algunos fallaren en las vinnas caçando con galgos o con rredes o con perro o con vallesta que peche diez maravedís cada persona por cada vez" ${ }^{57}$.

Pero la tradicional estructura clausular, de la que hablábamos en un comienzo, llega a su ruptura máxima cuando encontramos en medio de la redacción articular la solemnidad de algún preámbulo. Algo que se ha de comprender mejor si observamos con atención algún ejemplo en la compilación de las primeras ordenanzas arriacenses. En ellas se ha encontrado un prototipo con un orden ciertamente determinado: expositivo, preámbulo, dispositivo, sanción, preámbulo y sanción.

Este laberinto de formalidades, aun resultando poco usual, no sería sorprendente si no fuese por la aparición de dos preámbulos. Esta parte del llamado cuerpo del documento se hace manifiesta en escasas ocasiones y generalmente en documentos que gozan de una estructura con gran solemnidad clausular. Es por ello que difícilmente aparece en los documentos expedidos por la escribanía concejil. La característica principal del preámbulo, consiste en plasmar consideraciones generales que no hacen referencia a las ideas puntuales del documento, sino a declaraciones sobre moralidad, oportunidad de los acuerdos, legalidad de los mismos, referencias a leyes arcaicas o a preceptos de la lejana antigüedad clásica, e incluso, a citas bíblicas. Todo ello fuera de la integridad redactora del contenido y, por ende, sin manifestar su necesidad para la confección del diploma, más allá de la mejora estética en su composición redactora. Es por ello que su aparición en un manuscrito emanado de un concejo es cuando menos curiosa, pero si además se halla entremezclado con las cláusulas fundamentales de un artículo pasa a ser sorprendente. Por último, si aparece otro ejemplo apenas unas líneas más tarde, resulta de una categoría reseñable.

Consiguientemente reproduciremos completo el artículo donde aparece desarrollada dicha estructura, señalando las partes que la componen y comenzando por el expositivo que aparece introducido por el conocido íncipit "otrosi", al igual que en el resto de los artículos:

"Otrosí, por rrazón que es fama pública por la villa de Guadalfajara que quando algún alcallde o jurado manda prender algún ome por alguna cosa

\footnotetext{
56 Idem.

57 Idem.
} 
que aya de fazer execución, ansí por devda que devan o por cartas o por otra manera qualquier que sea, que quando el sayón o el andador va a prender quel defienden eso mismo (sic) prenda e después que van los alcalldes e que les defienden la prenda, e después que llaman al conçejo que los vayan a ayudar a los prender e esto que lo an de uso e de costunbre" ${ }^{58}$.

A continuación, comienza un solemne preámbulo que añade vistosidad retórica y diplomática al apartado:

"E los buenos usos e buenas costunbres deven ser guardadas y las cosas malas deben ser estrañadas e aborrecidas de aquellos en quien mora la justiçia e el derecho, que son buenos. E estos a tales que fazen las dichas anparas e defendimientos y laten de gran despreciamiento e grande soberbía de sus coraçones, e los omes non pueden aver conplimiento de derecho e porque las grandes osadias naçe gran daño a la tierra e porque es derecho que las cosas muy despreçiadas y muy sueltas en la tierra que viene mucho daño e mal, ansí como esto es, esto faze que de derecho es avido por derecho" ${ }_{59}$.

Una vez desarrollado este largo y literario preámbulo continúa un breve dispositivo, entronizado por la locución "por ende", que da lugar a una sanción recogida con tono formulario:

"Por ende, acordamos que qualquier ome que anparare al andador que peche la pena que es acordada, a quien anparare el juez que sea preso e que no sea suelto de la prisión fasta que de la prenda que anparó e defendió" ".

Y es en este momento cuando aparece un nuevo preámbulo que genera nueva enjundia y atractivo a lo dispuesto, por lo sugestivo del relato:

"Que cosa santa es obediençia a los mandamientos que están en lugar de Dios e de los señores y cosa aborreçedera deve ser de los sobervios e manparadores de lo que manda fazer la justiçia e por la obediençia venían los omes en folgura y en paz"'61.

\footnotetext{
AMGU 1H0052, Ordenanza XXI, f. XIr.

AMGU 1H0052, Ordenanza XXI, f. XIv.

Idem.

${ }^{61}$ Idem.
} 
Nuevamente la sanción marca el ritmo de las cláusulas, esta vez hasta el final del capítulo, previendo castigos no solo para el infractor, sino además para aquellos que le amparasen, llegándose a apelar a la propia reina en el caso de que los inculpados fueran oficiales del concejo:

"Y el juez que esto non fiziese, seyéndole mandado por los jurados o por los alcalldes o por qualquier de ellos que lo prenda el jurado e el alcallde que se lo mandare e el conçejo que le ayude e demás que pueda prender al sobervioso ynjurioso que defendió e anparó la prenda e si algunos de los del conçejo non se quisyeren yr con el jurado o con el alcallde a fazer esto seyendo afrontado que lo enbien a mostrar al alcallde o el jurado a nuestra señora la rreyna porque ella pueda escarmentar lo que su merçed fuere" "2.

Con la lectura del último artículo legislativo de cualquiera de las tres agrupaciones ordenancistas deberíamos pasar al escatocolo, donde se habrían de encontrar las cláusulas validadoras y protocolarias finales, más nada de esto ocurre pues con la última palabra del postrer artículo acaba la transcripción de las ordenanzas. No se ha de olvidar que en todo lo que concierne a los aspectos diplomáticos, las ordenanzas estudiadas quedan, como se ha visto, albergadas material y jurídicamente dentro de los documentos que las insertan, por lo tanto se han de dar por válidas las cláusulas compartidas.

\section{La punición como control del abastecimiento urbano}

Aunque el objetivo de este artículo reside principalmente en la configuración diplomática de las normativas presentadas se hará un acercamiento a ciertos temas contenidos en las mismas, que resultan transcendentales en la cotidianeidad de los grupos urbanos medievales, pero siempre desde la perspectiva puntual del citado ordenamiento.

De entre todas las regulaciones que se pretendían imponer a través de estas ordenanzas antiguas de Guadalajara destacan sobremanera, sin olvidar otras naturalezas necesarias, aquellas que inciden sobre el abasto de la villa. Lo hacen por medio de contrastadas intervenciones que buscaban generar un bloque cohesionado. A través de este sistema se mejoraba el visado de todos los contenidos referentes al suministro de mercancías con destino a la alimentación de sus habitantes ${ }^{63}$.

Las normas otorgadas en mayo de 1341 presentan, a modo de introducción sobre el control de abasto, un total de siete preceptos que pueden conformar un capítulo fac-

\footnotetext{
62 Idem.

63 Es de destacar la teoría de Sombart sobre las tres etapas del desarrollo de la economía a través del comercio. Economía individual (practicada en clanes y tribus en la Prehistoria, o en sociedades en creación durante la antigüedad), transitoria (representada en las ciudades medievales) y social (amparada por las tendencias modernas y contemporáneas del capitalismo, socialismo y otras). SOMBART, Lujo y capitalismo.
} 
ticio. Dicho articulado adquiere una eficaz fortaleza legislativa sobre la gestión de la compraventa de productos alimenticios. En su redacción se desarrollan un elenco de criterios que, por medio de la vigilancia de las pesas y medidas utilizadas en las mercancías expedidas en el mercado, avalan la protección del comprador. La mayor parte de los mismos hacen alusión explícita a las inspecciones sobre los citados productos. Este conjunto de normas finaliza con otro pequeño apartado de tres ordenanzas en las que se recogen los distintos arbitrios que se imponían a estos productos.

Las dos agrupaciones reguladoras que se hicieron durante el mes de diciembre de 1346 resultan más exiguas en su desarrollo, tal vez por la proximidad temporal, apenas un lustro, de la aprobación del anterior corpus. Por lo que respecta a las datadas el 1 de dicho mes, apenas se halla una norma que responda a la gestión del abastecimiento, correspondiendo el resto de los reglamentos a cuestiones diversas. En un escaso margen de tiempo, apenas tres semanas, los oficiales redactores pautaron nuevas medidas correspondientes a la cuestión alimentaria que regulan el pescado, la caza, el queso y algunos frutos. Los artículos sancionados tienen un perfil sesgado hacia la cuestión de la regatonería por su enorme influencia en los precios. El concejo de Guadalajara siempre mantuvo un empeño para concluir, o al menos controlar, este penoso y controvertido problema que distorsionaba el devenir de la regularidad proveedora.

El abastecimiento medieval implicaba una compleja gestión llevada a cabo por heterogéneos agentes económicos que representaban a los tres grandes colectivos: los productores, los consumidores y los reguladores de las normas. Una vez conocidos los actores principales, el mejor juicio de la táctica abastecedora pasa por valerse de los principios básicos de economía general sin olvidar que las finanzas de la Edad Media no conocían las premisas contemporáneas, pero sí que puede adaptar a un modelo competitivo básico que nace de tres proposiciones obligatorias. En primer lugar, es ineludible conocer el alcance que sobre lo ofertado han de exhibir los compradores, por otro lado, la clara búsqueda de un beneficio que demandan los productores, que en cualquier caso ha de resultar elevado, y, por último, que los mercados se muestran como sistemas finalistas. Todo análisis económico sobre compraventa carece de la certidumbre necesaria, siempre que cuente con una variable para aplicar una regulación en las licitaciones habituales, lo que lleva a entender el mercado medieval como un modelo de competencia imperfecta ${ }^{64}$. La mejora en el suministro alimentario conoció en el mundo medieval un salto importante a partir de la necesaria, pero precaria, transformación del siglo $\mathrm{X}^{65}$. Alternativa que conllevó unas claras reformas en la estabilidad política, una cierta disminución en el número de conflagraciones y que además contribuyó a un lento, pero progresivo acrecentamiento de la población. El aumento del número de mano de obra empleada en todos los menesteres de la producción agraria y ganadera, junto con algunos avances en los útiles de labranza, permitió una serie de progresos en la consiguiente cadena alimentaria. Dichos perfeccionamientos alentaron la existencia de excedentes en el

\footnotetext{
64 Escribano ABAD, Abastecer a la ciudad medieval.

65 Cuéllar, y Parra, "Las ferias medievales", pp. 103-117.
} 
mundo rural, lo cual facilitó que el comercio de compraventa basado en la producción sobrante se volviera usual, a la vez que se lograban una serie de progresos en el sustento en los grupos sociales urbanos ${ }^{66}$.

Los parámetros existentes en los modelos de estudio económico que tratan sobre los condicionantes en los intercambios de productos no se pueden aplicar en su totalidad al mundo medieval. Aunque, por otro lado, sí resulta factible ensayar otros elementos y actuaciones que nos permitan conocer la intervención del concejo por medio de una serie de disposiciones en busca del control absoluto de las transacciones abastecedoras ${ }^{67}$. El cabildo, en su afán de normalizar las actuaciones encaminadas al completo suministro de la población, genera normas, a veces demasiadas, que acaban por perfilar un elevado número de estándares. Algunos de estos modelos resultan contradictorios con la imagen de plena protección que pretender mantener los gobernantes de la población. ¿Estamos quizá ante un elevado número de patrones aparentemente contradictorios? Tal vez sea una propuesta con difícil dictamen en un mundo sumamente ordenancista y altamente protector. No obstante, todo ello no impide que algunas de estas pautas parezcan tender hacia el monopolio. Este camino genera una alta desprotección en la iniciativa individual del comprador, sobre todo porque quebranta el sistema de libre competitividad. La elevada importancia que mantenían dichas transacciones en los terrenos sociales y económicos distaba mucho de estar cercana al que se sustenta en la actualidad.

Se ha convenido que a lo largo de la Edad Media existió un claro intervencionismo económico por parte de los municipios, que se hace visible a través de una penetración en la red comercial. En ningún caso las actuaciones del gobierno concejil fueron el resultado de una actividad gratuita, sino de una búsqueda de corrección en aquellas desviaciones de precios y de medidas que el quehacer cotidiano, la ambición y la rapacería propiciaban. Los concejos procuraron el bienestar de la población generando originales sistemas de abastecimiento, que favorecían sobremanera a los vendedores locales frente a los foráneos por medio de una serie de medidas monopolistas y proteccionistas. En muchos casos este sistema dificultó el crecimiento económico de las villas. Igualmente se deben valorar los aprietos para el libre acceso a las mercancías en un mundo donde existieron grandes impedimentos para el libre tránsito debido a los condicionantes logísticos ${ }^{68}$.

En medio de la problemática surgida por los sistemas de abastecimiento libre surge una contradicción. Es el propio mercado quien la resuelve espontáneamente por medio de la figura de los regateros o regatones. Estos personajes podían ser de cualquier extracción social, religiosa o de género, tal como vemos en estas ordenanzas, donde aparecen cristianos, judíos y moros, de ambos géneros ${ }^{69}$. Los regateros y regatonas fueron una suerte

\footnotetext{
Caunedo Del Potro, "El desarrollo del comercio medieval", pp. 201-220.

Aguadé Nieto, y Cabañas González, "Comercio y sociedad urbana", pp. 487-489.

Arízaga Bolumburu, "El abastecimiento de las villas", pp. 293-316.

AMGU 1H0052, Ordenanza XIII, f. VIv.
} 
de especuladores que compraban su mercancía a los productores y después la llevaban a otras localidades, donde había necesidad de ellas, para obtener un provecho considerable. Efectivamente, la oferta de productos presentada generalmente por el productor se complementa por la llevada a cabo por los regatones, una figura tremendamente discutida en la historiografía medieval. La mayor parte de los autores han considerado que esta figura del regatón, más próxima al delincuente que al comerciante, resultaba perniciosa para el desarrollo económico del concejo ${ }^{70}$. Del mismo modo, no les han faltado tenaces defensores que han utilizado sesudas disquisiciones en su defensa ${ }^{71}$.

En las ordenanzas presentadas se aprecian unas normas altamente restrictivas que condicionan la compra de determinados artículos primordiales en la alimentación habitual a los citados ejecutantes. Para ello se sirven de una serie de preceptos que marcan las penas que han de sufrir aquellas personas que, en virtud de una conducta ilegal, procuren comprar o vender fuera de los horarios establecidos. Generalmente, las normativas municipales marcaban los tiempos comerciales por medio de las campanas de las iglesias y monasterios de las villas. Como ejemplo, podemos mencionar el funcionamiento de la mercadería de la sal en la villa estudiada. La compra de sal bajo el sistema del por mayor era común debido a su trascendental jerarquía en el aliño de los alimentos. Este producto resultaba muy codiciado por regateras y regatones que obtenían unos cuantiosos beneficios con su adquisición en los negocios de la villa y su posterior venta en las aldeas cercanas. La compra de este producto en la villa de Guadalajara quedaba vedada hasta que se hubiese producido los toques del mediodía provenientes de la iglesia de San Gil. La pena de incumplimiento era de 10 maravedís, que se repartían en tres partes, una para el arreglo de los adarves, otra para los hombres buenos que la reina había nombrado como sus representantes, y el último tercio para los almotacenes encargados de la punición de los infractores ${ }^{72}$.

Igualmente, se ejercía un férreo control punitivo sobre aquellos descontrolados que venían a la villa a vender el citado género por medio de una tasa fija de un celemín de sal, cada vez que comparecieren en las calles de la misma. Por el contrario, a los vendedores habituales del mercado, que, a ciencia cierta, mantenían un puesto fijo y abastecían con regularidad a los vecinos, sólo se les cobraba una vez al año. Estamos ante una clara desigualdad normativa del concejo ante ambos modos de entender el comercio menor que, por su carácter oportunista, penaba a los regatones con una carga mayor ${ }^{17}$.

\footnotetext{
70 Especialmente grave resulta la definición que sobre estos personajes expone Chacón Jiménez, que llega a llega a acusarlos de enriquecerse causando el hambre de los demás. ChACón JimÉnEZ, "Una contribución al estudio de la economía", pp. 211-262.

71 Escribano Abad, acomete el análisis de dos perfiles diferenciados dentro del mismo personaje. Una primera visión que los presenta como especuladores que propician la carestía, y una segunda, como coadyuvantes al reparto de las mercancías procedentes de unos lugares donde hay excedentes hacia otros que se encuentran en estado faltante, lo cual en algún modo ayuda a la estabilización de los precios. EsCRIBANo ABAD, Abastecer a la ciudad medieval.

72 AMGU 1H0052 Ordenanza XIII, f. Vv

73 Idem.
} 
Así mismo se prohibía a estos negociantes alternativos que hiciesen actividades con otros productos alimenticios considerados de carácter menor, tal como las frutas, los huevos o los derivados de la leche. El sistema era similar, prohibir todo tipo de actividad antes de la campana de San Julián y, en su defecto, multar a los infractores con la aludida multa de diez maravedís, dividiendo lo obtenido entre el arreglo de los muros, los hombres buenos y los jurados ${ }^{74}$. Finalmente, en las transacciones referidas a animales vivos como ánsares, gallinas y otras aves, se les imponía un maravedí de multa por cada vez que se les pillase en flagrante delito, además de la pérdida de lo comprado.

En las normas de 22 de diciembre de 1346, se insiste en que los regateros que deseen comprar cualquier producto el día del mercado habrán de esperar la consabida señal de la campaña de San Julián porque en caso contrario perderían lo comprado. Cuando los abastecedores regulares traían productos a vender a la villa, los regateros aprovechaban para abastecerse, pero por su calidad de comerciantes irregulares, no podían comprarlos hasta el día siguiente del registro de su llegada. Por medio de tres ordenanzas quedaban obligados a esperar a que hubiesen volteado la campana que indicaba la tercia, además de correr el riesgo de perder lo comprado y de pagar diez maravedís de multa. Todo ello en la línea de lo que había sido promulgado en las políticas ordenancistas del lustro anterior ${ }^{75}$.

En los citadas tres reglamentos se detallan los géneros que llegaban a la villa y estaban vetados a los regatones. La primera nos puntualiza los productos procedentes del reino de Murcia: las pasas, los higos, las peras, las almendras y el arroz ${ }^{76}$. Los regateros estaban obligados a venderlos a los precios predeterminados por el concejo, bajo el correctivo consabido de los diez maravedís.

El sistema de ventas de los regateros les llevaba a entrometerse en todos los sectores. De manera que dichos individuos abastecían a sectores de la población que demandaban productos tan divergentes como el hierro o la cebada, que son tratados en los siguientes artículos. Por medio de los mismos obligaban a que el citado cereal se vendiese limpio y enjuto, lo que llevaba a trabajos previos de descarnado de las espigas, que mermaban las ganancias de los presuntos competidores desleales ${ }^{77}$. En cuanto al metal, un objeto de deseo en las labores emergentes por medio de útiles férricos, las obligaciones se concretaban en vender al peso y respetar el coto impuesto por el concejo ${ }^{78}$.

De igual modo se aplicaba este acoso impositivo al régimen general de pesos y medidas necesarios en la organización mercantil. En el medievo se consideró de capital importancia la práctica de dicho régimen, que concluyó siendo el soporte de la imparcialidad en las transacciones comerciales. Existen variadas teorías que intentan justificar el origen

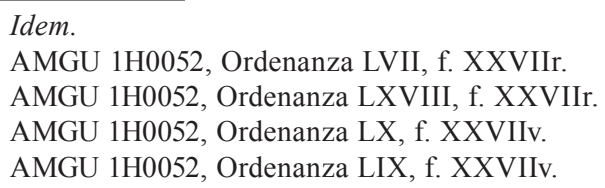


de tan elevada importancia. En primer lugar, las avaladas dentro de las ideas religiosas y filosóficas que defienden pensadores, como Tolomeo de Lucca, ya en el siglo XIV ${ }^{79}$, hasta las propugnadas por algunos teóricos economistas de nuestros días ${ }^{80}$.

La posible influencia del pensamiento griego y posteriormente del romano en el ascendiente de la espiritualidad que aportaba la idea de las proporciones ${ }^{81}$, favoreció que los concejos castellanos hicieran suyas aquellas premisas de la antigüedad. Esta manera de pensar, sistematizada a través de disposiciones regulares, fue la base de un comercio que buscaba estar exento de fraudes por medio de una equitativa combinación de pesos y medidas. Todas las cuales debían estar debidamente custodiadas para su honrada utilización por los oficiales del concejo ${ }^{82}$.

En pura lógica, la perseverancia que mostraban las administraciones concejiles en perseguir dichas estafas estaría en relación directa con el elevado número de pillajes que hiciesen los vendedores y con lo frecuentes que resultaran. Para dichas intendencias, resultaba muy importante vigilar con presteza la honestidad de los mercaderes, y un momento clave para ello es el instante mismo de la venta. Las ordenanzas reflejan en su desarrollo este pensamiento intentando remediar desde el propio municipio los comportamientos irregulares. Desde el comienzo aspiraron a la autorregulación por medio de la correcta restauración de los utensilios que eran usados por los oficiales concejiles y que, por el uso cotidiano, podían deteriorarse o gastarse. Este sistema conllevaba constantes revisiones y los mencionados cambios en los instrumentos utilizados, hasta alcanzar la máxima certidumbre en la precisión de las medidas usadas en los mercados de la localidad ${ }^{83}$.

En las ordenanzas de 1341, tanto en la norma II como en la XXXII, se acomete la labor de regulación de las pesas utilizadas para expedir la venta de la carne, procurando que no anden faltas de peso, de tal modo que los compradores puedan cotejarlo por medio de un peso que existía de antaño en la plaza del mercado ${ }^{84}$. Igualmente, debido a la peculiaridad del producto que se podía suministrar en grandes o pequeñas cantidades, se disponía de un amplio abanico de pesas que iban desde el arrelde de cuatro libras, seguido de cuarto, medio y ochavo ${ }^{85}$

La única obligación irrenunciable era que todas las pesas fuesen de hierro y que presentasen el sello del concejo. Un acto aparentemente simbólico, pero sumamente significativo en la imagen del concejo como custodio de los derechos ciudadanos. Los pesos

\footnotetext{
79 Tolomeo da Lucca escribió una obra, De Regimini Principum, como apéndice de las enseñanzas de su maestro Tomas de Aquino. En dicha obra aboga por la necesidad absoluta de los pesos y medidas. Revisado y analizado en BLythe, On the Government of Rulers.

80 Algunos estudiosos actuales se hacen eco de las teorías platónicas basada en los niveles universales y particulares, por la que se pretende justificar la idea de medida. WOOD, El pensamiento económico, pp. 130-131.

81 Kula, Las medidas y el hombre.

82 Sánchez Martín, "Pesos y medidas", pp. 405-414.

83 Castaño Álvarez, El libro de las pesas.

84 AMGU 1H0052, Ordenanza II, f.IIIv

85 AMGU 1H0052, Ordenanza XXXIV, f.XVIv.
} 
propios del concejo también eran motivo de comprobación ${ }^{86}$. Para ello se computaban siguiendo las indicaciones del marco de Burgos, del que dejaban cumplida cuenta de sus características ${ }^{87}$.

En productos de tanta demanda como el trigo, que se vendían por grandes cantidades, debieron producirse discordancias repetidas. Esto motivó que en la ordenanza XXXII se estableciese tajantemente que las medidas de capacidad serían la fanega toledana, junto con la media fanega, el celemín y el medio celemín ${ }^{88}$. Únicamente, se ponía como condición irrenunciable que la fanega tuviese doce celemines y todas las medidas utilicen el sello del concejo como garantía, debido al sentido transcendente que se daba a la figura de la impronta que aportaba un mensaje de seguridad ${ }^{89}$. Los modelos que no cumpliesen este requisito eran retirados y sus dueños pagaban diez maravedís.

Las medidas de capacidad utilizaban los patrones de Toledo, para la comprobación del $v^{\text {vino }}{ }^{90}$. En este sentido, según la ordenanza VII, cada vez que algún vendedor en el mercado o en alguna taberna cambiaba la medida física, estaba obligado a llevar la nueva al almotacén para que éste se la validase. Del mismo modo, se reconoce en dicha ordenanza que cualquier vecino, principalmente los comerciantes, será libre de comprar medidas ${ }^{91}$. Si los almotacenes encontraban alguna medida que no se adaptase a lo prescrito, los infractores debían pagar idéntica multa de diez maravedís y les rompían la pauta en la puerta de la taberna $^{92}$. Estos hechos, producto de la intervención de los oficiales concejiles, buscaban que los productos que se expendían respondieran a unos parámetros precisos de calidad y de cantidad, de tal suerte que no se engañase a los compradores.

Es de reseñar que la vigilancia de las medidas podía trascender del hecho de la compraventa mercantil para alcanzar niveles de mayor envergadura económica, tales como el control de las medidas para arquear las heredades. El alto nivel de engaño sobre las medidas reales de las tierras que se vendían forzó al concejo a dictaminar una ordenanza para usar sus propias regulaciones; transformado de ese modo en agrimensor local, incluso exigió la presencia del sello municipal como garantía de la precisión geómetra. También existía la posibilidad de otros tipos de medición, amparada en algún tipo de privilegio o carta real, y para ello se prohibió que los vendedores de tales heredades se acogiesen a cualquier ley no expresada en la normativa municipal. Ante tal eventualidad y ante las tres primeras veces, los infractores eran inculpados a pagar la pena

\footnotetext{
Bonachía Hernando, “Abastecimiento”, pp. 85-162.

AMGU 1H0052, Ordenanza XXXV, f. XVIv

AMGU 1H0052, Ordenanza XXXII, f. XVv.

MenÉndez Pidal De Navascués, Los sellos en nuestra historia.

AMGU 1H0052, Ordenanza XXIII, f. XVr.

AMGU 1H0052, Ordenanza VII, f. IVv.

92 Sobre al abastecimiento del vino y la protección del producto local en la zona de Tajo. IzQuiERDo Benito, Abastecimiento y alimentación en Toledo. López Villalba, "El abastecimiento del vino", pp. 143-184; Puñal Fernández, "La introducción y el comercio del vino", pp. 185-212.
} 
acostumbrada de 10 maravedís. Si alguno de ellos continuaba en su obstinación, a la cuarta ocasión se le condenaba a un mes de cárcel ${ }^{93}$.

Una vez que los productos se encontraban en las tablas del mercado preparados para su comercialización, comenzaba una segunda ronda de vigilancia, esta vez sobre las propiedades de la propia mercancía. Como ejemplo significativo destacamos la norma que trataba de evitar que, por medio de la picaresca se pudiese encubrir una carne de menor calidad para hacerla pasar por algún producto particularmente exquisito ${ }^{94}$. Los casos más comunes eran el cambio de vaca por carnero, buey por vaca, cabra por cabrón o puerca por puerco; un intercambio que podía favorecer unas ganancias extras a los transgresores de la norma ${ }^{95}$.

Entre el resto de los variados aspectos recogidos en estas ordenanzas antiguas de Guadalajara se podrían reseñar las rentas del concejo, tales como la pregonería, los ríos, viñas o las caloñas; junto con los derechos concejiles sobre algunos productos y determinados preceptos sobre los oficiales municipales.

\section{Conclusiones}

Las particularidades más destacadas de las ordenanzas antiguas de Guadalajara recaen sobre su temprana redacción, máxime si la comparamos con otros ejemplos destacados en la zona geográfica, como las leyes más pretéritas conservadas para la ciudad de Toledo, que están datadas en $1400^{96}$. Igualmente se enfatiza, la extensa regulación de la política comercial que presentan en busca de un beneficio para la villa. Esta actuación se encuentra dentro de la línea intervencionista que siguieron las reinas propietarias de Guadalajara con tono benefactor de carácter general, por medio de ayudas a monasterios y conventos, y a ciertos emprendimientos de la población ${ }^{97}$.

Primeramente, uno de los intereses más sobresalientes de la corona es establecer unas pautas de control mercantil gracias a una férrea disciplina normativa. Esta maniobra se sustentaba por medio de la continua salvaguardia de los vendedores locales sobre los eventuales. A los comerciantes no controlados por el concejo se les perseguía duramente por medio de diversos procedimientos punitivos, que rebajaban el beneficio de los mismos. La falta de rentabilidad les forzaba al abandono de la actividad. Esta

\footnotetext{
93 En lo tocante a la temática de las heredades y sus variados conflictos. Plaza De Agustín, "La usurpación de bienes", pp. 459-485.

94 BANEgAS LóPEZ, Europa carnívora.

95 AMGU 1H0052, Ordenanza III, f. IIIr.

96 Morollón Hernández, "Las ordenanzas municipales", pp. 265-439.

97 Se debe resaltar que la figura de doña María de Portugal, esposa de Alfonso XI, autora de estas ordenanzas, al igual que las del resto de las reinas que fueron señoras de la villa, están a la espera de un estudio profundo que aporte a sus figuras históricas la visibilidad que merecen. Recuperar a estas mujeres, para la historia de Guadalajara como villa y para la historia de Castilla como reino, debe ser un reto a conseguir dentro de las nuevas líneas de investigación que se están en plena ebullición en la historia medieval española. Pérez FLoRES, y Del Val Valdivieso, "La Historia de las mujeres", pp. 101-127.
} 
imbricación de los preceptos mercantiles daría lugar a una oligarquía urbana que, por medio de entramados comerciales basados en el oligopolio, buscaría un beneficio rápido que acabó perjudicando a los consumidores ${ }^{98}$.

El mercado fue uno de los elementos que caracterizaba los núcleos urbanos, llegando a dinamizar los cascos centrales de las villas. Las ciudades castellanas no fueron el resultado de focos colonizados y urbanizados por mercaderes, al estilo italiano o flamenco ${ }^{99}$. Pero en cualquier caso dichas ciudades tuvieron comportamientos desarrollistas enfocados a la provisión alimentaria de las mismas. Desde muy temprano se dictaron normas que favoreciesen la instalación de las tiendas, tablas o comercios para expender los productos comunes, como carnes, pescado o pan con buenas condiciones sanitarias, al igual que se renovaron caminos, puentes y entradas a las poblaciones.

La sobreprotección que marcaban las líneas de desempeño de los gobiernos municipales en los siglos medievales fue consustancial a su forma de plantear el mundo mercantil. Estaba por llegar el triunfo de los obligados, que aseguraban todo el año la provisión de alimentos esenciales. Mientras tanto, el proceso del mercado se convertía en un sobresalto proveedor en el que perduraba el sistema de tiempo corto junto con al amparo del producto local. Sin olvidar la influencia que tuvieron las épocas de escasez o abundancia, con la consiguiente regulación de precios. En el supuesto de un desabastecimiento, total o parcial, se producía la aparición de los regateros que perturbaban el sistema protector, por medio de su conocido procedimiento de compra-venta. El concejo promulgaba leyes para la inmediatez, alejándose de la realidad que le hubiese permitido mantener una previsión estructural para combatir las épocas de penuria.

En medio de las amplias, continuas y obsesivas leyes proteccionistas, destacan las dictadas para el control de las cantidades vendidas. Existía una auténtica preocupación para evitar la perversa utilización de las pesas y medidas. Estos patrones fueron objeto de numerosas disposiciones para que los almotacenes, oficiales municipales inspectores del mercado, pudiesen comprobar todas las pesas utilizadas por los vendedores. Bien es cierto, que las pesas se podían deteriorar con el paso del tiempo, pero igualmente se podían falsear o cambiar para obtener beneficios instantáneos. Estas pesas y medidas podían ser concejiles o privadas, porque la norma permitía que cada uno de los vendedores la adquiriese libremente, siempre que estuviesen visadas por los citados oficiales, y con la consabida autorización por medio del sello del concejo. Con estas normativas el concejo mantenía todo un inflexible, pero sumamente necesario, sistema de persecución hacia los incumplidores de la norma.

Por último, reseñar el principal objetivo de este trabajo, el análisis diplomático de los procedimientos documentales que utilizaron las ordenanzas municipales para defenderse de su habitual desprotección estructural. En efecto, muchas de las ordenanzas municipales que se conocen carecieron del esqueleto clausular necesario para establecer un análisis diplomático tradicional. Verdaderamente, la pluralidad de imágenes que aporta esta tipología

98 ESCRIBANO ABAD, "La regulación del mercado", pp. 109-137.

99 Ladero Quesada, y Quintanilla Raso, "La investigación sobre historia económica", pp. 69-96. 
es tan elevada que, en alguna de sus formas, no completa el muestrario de las fórmulas diplomáticas necesarias. Con este planteamiento, se ha trabajado en un modelo de análisis que perfilará un mejor conocimiento de las mismas.

Las ordenanzas fueron la solución a muchos problemas particulares que se generaban conforme crecían los poblamientos. No siempre fue fácil la aplicación de la regla. La confrontación entre los poderes fácticos económicos, políticos y sociales, desde la monarquía a la pequeña nobleza clientelar, junto con los patriciados urbanos, dificultaron la aplicación de la norma. Tras el empleo generalizado del ordenamiento de Alcalá de 1348 se volvieron a forzar vínculos con el poder real, que representaba el principio de legalidad más apreciable a partir de aquellas fechas ${ }^{100}$. Aunque, no fue por el más corto de los caminos por el que los grupos elitistas transitaron hacia los novedosos conceptos en la gestión de las urbes. Para la villa de Guadalajara se observa que todavía es temprano para distinguir el funcionamiento de una red clientelar. Los conjuntos de poder urbano que, enérgicamente amparados por la familia Mendoza, se han de establecer firmemente en dicha villa a partir de comienzos del siglo XV, todavía estaban en estado de embrión. ¿Se abandonan las viejas concepciones de derecho local que disfrazadas de privilegios forales fueron impuestas por la monarquía y las clases privilegiadas? ¿Estamos ante el comienzo de una etapa en la que prime el derecho particularizado? Evidentemente sí. Pero sin cambios traumáticos que rompan el sistema. Apenas, la certeza de que alejado un largo y pausado período de realización de añejas normas, se avisaba la llegada del tiempo de las ordenanzas. El universo urbano se presenta a mediados del siglo XIV como la antesala de un mundo en transición. Se estaban desentrañando una serie de perfiles que establecerán, entre otras cuestiones, el aspecto sumamente poliédrico de las villas y ciudades en los tiempos finales de la Edad media ${ }^{101}$.

\section{Bibliografía}

Aguadé Nieto, Santiago y Cabañas González, María Dolores, "Comercio y sociedad urbana en la Castilla medieval. La comercialización de la carne en Cuenca (1177-1500)", Anuario de Estudios Medievales, 14 (1984), pp. 487-489.

Alvarado Planas, Javier, Espacio y Fueros de Castilla-La Mancha (siglos XI-XV). Una perspectiva metodológica, Editorial Polifemo, Madrid, 1995.

Álvarez Palenzuela, Vicente Ángel, "La Corona de Castilla en el siglo XV. La administración central", Espacio, Tiempo y Forma, Serie III, Historia Medieval, 4 (1991), pp. 79-94.

Arízaga Bolumburu, Beatriz, "El abastecimiento de las villas vizcaínas medievales: política comercial de las villas respecto al entorno y a su interior", En la España

100 González Jiménez, Manuel, “La creación del derecho local”, pp. 339-363.

101 Bernardo Ares, "Las ordenanzas municipales", pp. 15-38. 
medieval, 6 (1985), (Ejemplar dedicado a La ciudad hispánica durante los siglos XIII al XVI. t. I), pp. 293-316.

Banegas López, Ramón Agustín, Europa carnívora. Comprar y comer carne en el mundo urbano bajomedieval, Editorial Trea, Avilés, 2012.

Barrero García, Ana María y Alonso Martín, María Luz, Textos de Derecho local español en la Edad Media. Catálogo de Fueros y Costums Municipales, CSIC-Instituto de Ciencias Jurídicas, Madrid, 1989.

Barrios García, Ángel, Monsalvo Antón, José María y Del Ser Quijano, Gregorio, Documentación Medieval del Archivo Municipal de Ciudad Rodrigo, Ediciones de la Diputación de Salamanca, Salamanca, 1988.

Bernardo Ares, José Manuel, "Las ordenanzas municipales y la formación del estado moderno", La ciudad hispánica durante los siglos XIII al XVI, Actas del Coloquio celebrado en La Rábida y Sevilla del 14 al 19 de septiembre de 1981. Sáez Sánchez, Emilio, Segura Graiño, Cristina y Cantera Montenegro, Margarita (coords.), En la España Medieval, n¹0-87, Tomo III, Madrid, 1987, pp. 15-38.

Blythe. J. M, On the Government of Rulers: De Regimine Principum. Ptolemy of Lucca with portions attributed to Thomas Aquinas, University of Pennsylvania Press, Filadelfia, 1997, t. 2º Capítulo 14.

Bonachía Hernando, Juan Antonio, "Abastecimiento, mercado local y control municipal. La provisión y comercialización de la carne en Burgos (Siglo XV)", Espacio, Tiempo y Forma, Serie III, Historia Medieval, 5 (1992), pp. 85-162.

Cañas Galvéz, Francisco de Paula, Itinerario de Alfonso XI. Espacio, poder y corte (1325-1350), Ediciones de la Ergástula, Madrid, 2014.

Carrilero Martinez, Ramón, "Diplomática municipal: las ordenanzas. Teoría y práctica", Anales del Centro Asociado de la UNED en Albacete, 9 (1987-1989), pp. 71-90. Castaño Álvarez, J.: El libro de las pesas y medidas, La Esfera de los Libros, Madrid, 2015. Caunedo Del Potro, Betsabé, "El desarrollo del comercio medieval y sus técnicas mercantiles. Ejemplos castellanos", Pecvnia, 15 (julio-diciembre 2012), pp. 201-220.

Corral García, Esteban, Ordenanzas de los Concejos castellanos. Formación, Contenidos y Manifestaciones, Taller gráfico Diario de Burgos, Burgos, 1988.

Cuéllar, María del Carmen y ParRa, Concepción, "Las ferias medievales, origen de documentos de comercio", Ecrire, Traduire et représenter la fête. Domingo Pujante González, Elena Real, Dolores Jiménez Plaza, y Adela Cortijo Talavera (coords.), Universitat de Valencia, Valencia, 2001, pp. 103-117.

ChACón JimÉnez, Francisco, "Una contribución al estudio de la economía municipal en Castilla. La coyuntura económica concejil murciana en el periodo 1496-1517”, Miscelánea Medieval Murciana, 3 (1977), pp. 211-262.

Diccionario de Autoridades (1726-1739), Real Academia Española, edición facsimilar. Madrid, 2013. 
Escribano Abad, José Luis: Abastecer a la ciudad medieval. Política concejil en el reino de Toledo (s. XIV-XV), Universidad de Alcalá (Servicio de Publicaciones), Alcalá de Henares, 2017.

Escribano AbAD, José Luis, "La regulación del mercado alimentario: el caso de la Guadalajara medieval", Espacio, Tiempo y Forma, Serie III, Historia Medieval, 21 (2008), pp. 109-137

GARCíA LóPez, Juan Catalina, La Alcarria en los dos primeros siglos de su Reconquista, Real Academia de la Historia, Madrid, 1894.

García de Cortázar y Ruiz de Aguirre, José Ángel. “Alfonso X y los poderes del reino". Alcanate. Revista de estudios Alfonsíes. 9 (2014-2015), pp. 11-40.

GonzÁlez Jiménez, Manuel, "La creación del derecho local y territorial andaluz. De Alfonso X a los Reyes Católicos" Initium. Revista catalana d'Historia del Dret, 33 (2006), pp. 339-363.

González Mínguez, César, "Aproximación al estudio del "movimiento hermandino" en Castilla y León”, Medievalismo, Boletín de la Sociedad Española de Estudios Medievales, I-II (1991-1992), pp. 34-35 y 29-60.

IzQuiERdo Benito, Ricardo, Abastecimiento y alimentación en Toledo en el siglo XV, Ediciones de la Universidad de Castilla-La Mancha, Excma. Diputación de Toledo, Toledo, 2002.

Keniston, Hayward (ed.), Fuero de Guadalajara de 1219, Princeton University Press, Princeton, Nueva Jersey, 1924.

Kula, W, Las medidas y el hombre, Editorial Siglo XXI, Madrid, 2012.

Ladero Quesada, Miguel Ángel y Galán Parra, Isabel, "Las ordenanzas locales en la Corona de castilla como fuente histórica y tema de investigación (siglos XIII al XVIII)", Anales de la Universidad de Alicante, 1 (1982), pp. 221-243.

Ladero Quesada, Miguel Ángel y Quintanilla Raso, Concepción, “La investigación sobre historia económica medieval en España (1969-1989). Conclusión”, Medievalismo, Boletín de la Sociedad Española de Estudios Medievales, 2 (1992), pp. 69-96.

Layna Serrano, Francisco, Historia de Guadalajara y sus Mendozas en los siglos XV y XVI, Instituto Jerónimo Zurita, Madrid, 1942, 4 Tomos. Reedición, Aache Ediciones, Guadalajara, 1988.

Loaysa, Jofré de, Crónica de los reyes de Castilla: Fernando III, Alfonso X, Sancho IV y Fernando IV (1248-1305), Edición a cargo de Antonio García Martínez, Patronato de Cultura de la Excma. Diputación, Murcia, 1961.

López Villalba, José Miguel, Diplomática Municipal Medieval de Guadalajara, Excma. Diputación de Guadalajara, Guadalajara, 2006. CD-Rom.

López Villalba, José Miguel, Las Actas de Sesiones del Concejo Medieval de Guadalajara, UNED, Madrid, 1997. 
López Villalba, José Miguel, "El abastecimiento del vino y su política proteccionista en el Alto Tajo (Siglos XIV-XV)”, Espacio, Tiempo y Forma, Serie III, Historia Medieval, 24 (2011), pp. 143-184.

Martín Prieto, Pablo, Los Fueros de Guadalajara, Excma. Diputación Provincial de Guadalajara, Guadalajara, 2010.

Martín Prieto, Pablo, "Notas sobre María de Portugal como señora de Guadalajara (1328-1356)", Espacio, Tiempo y Forma, Serie III, Historia Medieval, 24 (2011), pp. 219-236.

Martínez, Purificación, "La Crónica y la Gran Crónica de Alfonso XI. Dos versiones ideológicas del reinado de Alfonso XI", Hispanic Research Journal: Iberian and Latín American Studies, Vol. I, 1 (2000), pp. 43-56.

Menéndez Pidal de Navascués, Faustino, Los sellos en nuestra historia, Real Academia de la Historia, Boletín Oficial del Estado, Madrid, 2018.

Mignot, Caroline, "Le municipio de Guadalajara au XVème siècle, système administratif et économique (1341-1567)”, Anuario de Estudios Medievales, 14 (1984), pp. 581-609.

Monsalvo Antón, José María: El sistema político concejil. El ejemplo del señorío medieval de Alba de Tormes y su concejo de villa y tierra. Ediciones de la Universidad de Salamanca, Salamanca, 1988.

Morollón Hernández, Pilar, "Las ordenanzas municipales antiguas de 1400 en la ciudad de Toledo", Espacio, Tiempo y Forma, Serie III, Historia Medieval, 18 (2005), pp. 265-439.

Muñoz Romero, Tomás (ed,), Colección de fueros municipales y cartas pueblas de los reinos de Castilla, León, Corona de Aragón y Navarra, Imprenta de José María Alonso, Madrid, 1847.

Pareja Serrada, Antonio, Diplomática arriácense, Casa de Expósitos, Guadalajara, 1921.

Pérez Flores, Diana y Del Val Valdivieso, María Isabel, "La Historia de las mujeres en el siglo XXI a través del estudio de la Reginalidad medieval”, Revista de Historiográfica (ReVHisto), Del ayer al mañana. La historiografia de la historia de las mujeres, del género y del feminismo, 22 (2015), pp. 101-127.

PÉRez Villamil, Manuel, Relaciones Topográficas de España. Relaciones de pueblos que pertenecen hoy a la provincia de Guadalajara. Memorial Histórico Español, Real Academia de la Historia, Madrid, 1919.

Pino Rebolledo, Fernando: Diplomática Municipal. Reino de Castilla (1474-1520), Cuadernos de la Cátedra de Paleografía y Diplomática VI Universidad de Valladolid, Valladolid, 1972; y Tipología de Documentos Municipales (siglos XII-XVI), Secretariado de Publicaciones, Universidad de Valladolid, Valladolid 1991.

Plaza De Agustín, Javier, "La usurpación de bienes comunales y baldíos en Guadalajara durante la segunda mitad del siglo XV", Espacio, Tiempo y Forma, Serie III, Historia Medieval, 28 (2015), pp. 459-485. 
Puñal Fernández, Tomás, "La introducción y el comercio del vino en el Madrid medieval”, En la España medieval, 17 (1994), pp. 185-212.

Riesco Terrero, Ángel, “Análisis jurídico-diplomático de las Ordenanzas Reales de Bujía de 1531”, Espacio, Tiempo y Forma. Serie IV, Historia Moderna, 5 (1992), pp. 51-70. SÁnchez Gómez, Julio, De minería, metalurgia y comercio de metales. La minería no férrica en el reino de Castilla, Universidad de Salamanca, Instituto Geominero de España, Salamanca, 1989.

SÁnchez Martín, Aureliano, "Pesos y medidas medievales y modernas", Historia de Medina del Campo y su tierra. Nacimiento y expansión, Vol. 1, Eufemio Lorenzo Sanz (coord.), Ayuntamiento de Medina del Campo, Junta de Castilla-León: Consejería de Educación y Cultura, Diputación Provincial de Valladolid, Caja de Ahorros de Valladolid, Valladolid, 1986, pp. 405-414.

Sanz Fuentes, María Josefa: "Tipología Documental de la Baja Edad Media castellana: documentación concejil. Un modelo andaluz: Écija”, Archivística. Estudios Básicos., Sevilla, 1993, pp. 193-208

SAnz Fuentes, María Josefa: "De Diplomática concejil castellana en la Edad Media. Una nueva propuesta de clasificación documental", Sit liber gratus, quem servulus est operatus. Studi in onore di Alessandro Pratesi per il suo $90^{\circ}$ compleanno. Tomo I. A cura di Paolo Cherubini e Giovanna Nicolaj. Scuola Vaticana di Paleografía, Diplomatica e Archivistica, Città del Vaticano, 2012, pp. 535-548.

SOMBART, Werner, Lujo y capitalismo, Editorial Sequitur, Madrid, 2009.

SpRAndel, Rolf, "Notas sobre la producción de hierro en la Península Ibérica", Anuario de Estudios Medievales, 13 (1983), pp. 351-365.

Wood, D.: El pensamiento económico medieval, University of Cambridge, Cambridge, 2002. 
